\title{
PE Growth and Risk: Evidences from Value Investing in Thailand
}

\author{
Paiboon Sareewiwatthana \\ School of Business, National Institute of Development Administration, Bangkok, Thailand \\ Email: paiboon43@hotmail.com
}

Received 17 March 2014; revised 17 April 2014; accepted 24 April 2014

Copyright (C) 2014 by author and Scientific Research Publishing Inc.

This work is licensed under the Creative Commons Attribution International License (CC BY). http://creativecommons.org/licenses/by/4.0/

cC) (i) Open Access

\begin{abstract}
This study employed the concept of value investing, whereby PE, PEG, and PERG ratios were used for stock screening. PE is the basic price to earnings ratio; while PEG is the PE with growth incorporated. PERG is the PEG adjusted for risk factor. The concepts based on the hypotheses that stocks with low PE ratio, low PEG, and low PERG should generate higher returns than those of the market average. Data from the Securities Exchange of Thailand during 2002-2012 were used to test the hypotheses. Returns from portfolios with low PE, low PEG, and low PERG were computed and found to be better than those of the market average. Proxies for risk, the standard deviation of return and the beta coefficients, were used to computed PERG. Portfolios of low PERG using Standard Deviation as risk proxy appeared to provide better performances than those of using beta coefficient. All in all, PE appeared to be the best screening, providing the highest returns during the period tested.
\end{abstract}

\section{Keywords}

Value Investing, PE, PEG, PERG, The Stock Exchange of Thailand

\section{Introduction}

Value investing has been widely accepted. The approach of value investing makes use of fundamental analysis, a rational analysis of securities based on an understanding of the business invested. Significant weight of value investing is thus related to the analysis of company's through the use of various financial ratios.

One of the most popular financial ratios is the price to earnings (PE) ratio; whereby consideration focuses on stocks with low PE ratio, which reflected that such stocks had a price lower than their fair value when compared to earnings per share which could be achieved. However, the method of stock selection based on low PE ratio has been questioned regarding the growth opportunity. This leads to the approach where the company's growth 
is incorporated in the analysis, resulting in the price/earnings to growth (PEG) ratio. The use of PEG ratio is therefore a combination of value investing and growth investing concepts because it is a criterion which considers the stock price as compared to profit, along with the growth rate of the profit.

However, there are observations that the use of PE and PEG may overlook one of the most important factors that command the return, the risk. There have been very little literatures and empirical studies to test if the adjusted PE by both growth and risk, so-called PERG, could yield better performance than a plain PE and with additional growth indicator PEG. Although, there have been studies of benefits of using PE and adjusting PE with growth in Thailand, none of the researches have explored the benefits of explicitly adding risk factor into the stock selecting process. It is the intention of this study to combine both the growth and risk into the PE and to study if the new screening rule, PERG, could yield better portfolio performance. In addition to test the use of PERG, this study will examine which risk proxy, the conventional standard deviation of returns (SD) or the modern portfolio theory beta coefficient (beta), could yield better performance when used in determining PERG.

In the next section, related literatures are reviewed and summarized. Then the research methodology and data used in this study are discussed. Empirical results found in this study are then presented and analyzed. Lastly, conclusion, implications, and limitations together with suggestion for further study are discussed.

\section{Literature Review}

Researches in the recent years have found that value premium existed, both in developed and developing markets. Value investing strategy outperforms growth strategy across countries. A number of studies have explored the situation where the price of stocks traded in the market was not consistent with fundamental information, and studied the causes of this irregularity. These include researches by Schatzberg and Vora [1], Robichek and Bogue [2], Reinganum [3] and Fama and French [4]. Most of the studies reported that investing in stocks which had low value of certain financial ratios such as price to earnings, price to book value, and return on equity, yielded better returns than the market average. Fama and French [5] and Petkova and Zhang [6] reported that value stocks had higher risk than average stocks and because of the higher risk premium, their prices were thus lower.

Due to the conflict of perspectives on price and growth opportunity between value stocks and growth stocks ${ }^{1}$, the PEG ratio became more widely discussed. However, academic work on PEG ratio was not much available. Holt [7] conducted a study on returns from growth stocks selected based on PE ratio as compared to other securities; while Malkiel [8] proposed methods for growth stock valuation as compared to non-growth stocks. Easton [9] presented a model for assessing expected profitability and growth of returns employing PEG-based ranking, and found that the return being estimated correlated significantly with the level of the PEG ratio.

Estrada [10] selected stocks in the US stock markets during 1975-2002 using PE, PEG, and PERG ratios. He concluded that strategies based on PERG ratio, with adjusting PE ratio by both growth and risk, outperformed those based on PE and PEG. The conclusion is made based on the higher risk adjusted returns obtained from using PERG.

In Thailand, studies of value investment strategies have been limited. Sareewiwatthana [11] studied the stock selection methodology for investing in the Stock Exchange of Thailand during 1996-2010 based on basic financial ratios such as PE, PB, ROE, etc., and found that the investment strategy based on these ratios could generate returns which significantly exceeded the market average. Maneesilasan [12] conducted a study on growth at a reasonable price (GARP) investment strategy by selecting stocks based on PEG ratio with the assumption that the rate of growth of profit generated by a company one year later was equal to the rate of change in average earnings per share of the last 3 years. The study result also showed that this strategy could generate higher returns than the market. Sareewiwatthana [13] showed that PEG ratio was effective in generating higher returns

\footnotetext{
${ }^{1}$ Value stocks are stocks with market price lower than the fair value of the company (undervalued) as assessed based on fundamental factors, e.g., dividends, sales, profits, etc. Investors who are interested in this category of stocks, called value investors, share a common viewpoint that stock exchange is inefficient, and as a consequence, profit could be generated from deviation of stock price. They believe that the stock price will eventually reflect the intrinsic value of the company. Stocks in this category have common characteristics of high dividend ratio, low $\mathrm{PE}$ ratio, and low $\mathrm{P} / \mathrm{B}$ ratio.

Growth stocks are stocks of companies, which are expected to perform well above the average, yielding higher growth rate in earnings. Companies in this category usually do not pay dividends, as they prefer to use the retained earnings to invest in expanding fast-growing business. Expectation for the good future of such company causes the stock to be sold at a price higher than fair value (overvalued). Growth stocks are also known as Glamour stocks.
} 
than the average return throughout the analysis over 1999-2010. Panyagometh [14] compared equally weighted value stock portfolios with Mean-Variance portfolio optimization weighted value stock portfolios and market capitalization weighted value stock portfolios in the Thai stock market and concluded that the portfolio management theory could be applied together with value investing to yield higher returns. Sareewiwatthana, [15] evaluated portfolio performances using five ratios-price to earnings per share, price to book value, return on equity, return on assets, and dividend yield. The results show that all tested portfolios outperformed the market; while that of low PE stocks yield the highest return, He also found that using single ratio, invested portfolio outperforms those of using two, three, and four ratios and screening tools.

\section{Data and Methodology}

\subsection{Concept of Stock Price Valuation Based on PE, PEG, and PERG Ratios}

\subsubsection{Price to Earnings (PE) Is a Ratio between the Stock's Market Price and Earnings per Share a Company Generated in the Past Year}

This ratio shows how appropriate the current stock price is, comparing to earnings per share. If all stocks in the market offer fixed income at all times, the most interesting stock will be the one with lowest PE ratio. Moreover, PE ratio also reflects the view of investors toward a company in the future; how many times the net profit that the company is capable of generating the investors are willing to invest their money in. The formula used for calculating the ratio is as follows:

$$
\mathrm{PE}=\frac{\text { Price }}{\mathrm{EPS}}
$$

where Price $=$ price per share.

EPS $=$ earnings per share.

\subsubsection{Concept of Improving the Efficiency of PE Ratio by Incorporating the Growth Factor, the PEG} Ratio

PEG ratio is developed from PE ratio by dividing the PE with the long-term earnings growth rate. The PEG ratio depends on the measurement of value using the original PE ratio and the growth rate of the future profit. The PEG ratio can be calculated as follows:

$$
\mathrm{PEG}=\frac{\mathrm{PE}}{g}
$$

where $\mathrm{PE}=$ price to earnings ratio.

$g=$ earnings growth rate (annually).

\subsubsection{Concept of Improving the Efficiency of PE Ratio through the Use of PERG Ratio}

PERG ratio is developed from PEG by explicitly combining risk factor into the PEG ratio. The calculation of PERG is as follows:

$$
\mathrm{PERG}=\frac{(\mathrm{PE}) \times R}{g}=\mathrm{PEG} \times R
$$

where PE = price to earnings ratio.

$g$ = earnings growth rate (annually).

$R=$ risk factor.

\subsection{Research Data}

This study utilizes data from the Stock Exchange of Thailand during 2002-2012. The closing price at the end of February of each year was used as the starting price of the year, and the closing price at the end of February of the next year was used as the ending price of the year in order to align with the announcement of annual results of the listed companies. Earnings per share of the year which was announced within February of the following year was used as the earnings per share figure for calculating PE ratio. The growth rate, $g$, was calculated based 
on earnings per share of the past 3 years, and this figure was used as proxy of the growth rate of future earnings per share. Standard deviations (SD) of the portfolio returns were calculated. Bloomberg's beta coefficients (beta) of individual stocks were collected and averaged to be used as portfolio's beta. SDs and betas were used as proxies for risk.

\subsection{Research Methodology}

This study employed the concept of value investing, whereby PE, PEG, and PERG ratios were used for stock screening. The concepts were based on the hypotheses that stocks with low PE ratio, low PEG, and low PERG could generate higher returns than those of the market average. Performances of portfolios with low PE, low PEG, and low PERGs were evaluated. Two proxies for risk, SD and beta, are separately used as risk factor in this study.

Four patterns of portfolio holdings were constructed annually during the study period, namely:

- Portfolio A: investing in 30 stocks with the lowest PE ratio which was greater than 0 ;

- Portfolio B: investing in 30 stocks with the lowest PEG ratio which was greater than 0;

- Portfolio C: investing in 30 stocks with the lowest PERG-SD ratio which was greater than 0; and

- Portfolio D: investing in 30 stocks with the lowest PERG-beta ratio which was greater than 0.

The tests were further conducted to determine whether the selection of stocks through the use of PE, PEG, PERG-SD, and PERG-beta ratios were capable of generating higher returns than those of stock exchange's total return index investing. Each investment was evaluated over the period of one year. The selection process were repeated at the end of February March during 2002-2012. Annual portfolios' returns were compared to the total return index of the Stock Exchange of Thailand (SET TRI). Sharpe Ratios ${ }^{2}$ are then employed to measure performances after adjusted for risk. Returns from the portfolios using four different screening were then compared with one another. Value added of the four portfolios in 11 years period over 2002-2012 then compared with that of the market average.

\section{Empirical Results}

\subsection{Results from Stock Selection Using PE Ratio Compared to the Market Average}

Table 1 shows that when stocks were selected using the lowest PE ratios as screening, the returns were better than the market average in 8 out of 11 years. Furthermore, when Sharpe ratios were used to measure the portfolio performances, the results demonstrated that Sharpe ratios of the low PE portfolios were better than those of the market in 8 out of 11 years.

\subsection{Empirical Results from Stock Selection Using PEG Ratio Compared to the Market Average}

Table 2 shows that when stocks were selected using the lowest PEG ratios as screening, the returns were better than the market average in 6 out of 11 years. When Sharpe ratios were used to measure the portfolio performances, the results demonstrated that Sharpe ratios of the low PEG portfolios were better than those of the market in 6 out of 11 years.

\subsection{Empirical Results from Stock Selection Using PERG Ratio Compared to the Market Average Stock, Using Standard Deviation of Returns as a Proxy for Risk}

Table 3 shows that when stocks were selected using the lowest PERG-SD ratios as screening, the returns were better than the market average in 8 out of 11 years. When Sharpe ratios were used to measure the portfolio

\footnotetext{
${ }^{2}$ Sharpe ratios is a ratio developed by William F. Sharpe [16] that is used in analyzing the risk-adjusted returns. This makes it possible to compare returns on investment to make sure that the excess return is not due to increased risk. The higher Sharpe ratio indicates the higher investment efficiency. The value can be obtained as follows:
}

$$
\text { Sharpe Ratio }=\frac{r_{p}-r_{f}}{\sigma_{p}}
$$

$r_{p}=$ Portfolio's expected rate of return.

$r_{f}=$ rate of return on a risk-free asset (based on a 10-year government bond in this case).

$\sigma_{p}=$ standard deviation of the portfolio's rates of return. 
Table 1. Returns of portfolios selected by PE ratio compared to the market.

\begin{tabular}{cccccc}
\hline & Low PE & & \multicolumn{2}{c}{ Market average } & Differential \\
\cline { 1 - 3 } Year & Return & Sharpe ratio & Return & Sharpe ratio & $71.28 \%$ \\
2002 & $71.45 \%$ & 2.934 & $0.166 \%$ & -0.271 & $96.39 \%$ \\
2003 & $202.95 \%$ & 6.862 & $106.569 \%$ & 4.023 & $-15.95 \%$ \\
2004 & $-8.99 \%$ & -0.954 & $6.960 \%$ & 0.177 & $-8.31 \%$ \\
2005 & $-3.79 \%$ & -0.656 & $4.517 \%$ & -0.017 & $19.25 \%$ \\
2006 & $14.55 \%$ & 0.554 & $-4.698 \%$ & -0.627 & $-18.31 \%$ \\
2007 & $11.60 \%$ & 0.470 & $29.908 \%$ & 1.198 & $10.14 \%$ \\
2008 & $-36.26 \%$ & -1.178 & $-46.401 \%$ & -1.404 & 5.155 \\
2009 & $131.70 \%$ & 5.584 & $75.025 \%$ & 2.396 & $22.93 \%$ \\
2010 & $66.99 \%$ & 3.327 & $44.052 \%$ & 0.828 & $27.89 \%$ \\
2011 & $50.85 \%$ & 2.024 & $22.958 \%$ & 2.874 & $34.50 \%$ \\
2012 & $72.56 \%$ & 4.470 & $38.065 \%$ & & \\
\hline
\end{tabular}

Table 2. Returns of portfolios selected by PEG ratio compared to the market.

\begin{tabular}{cccccc}
\hline & Low PEG & \multicolumn{2}{c}{ Market average } & Differential \\
\cline { 1 - 3 } Year & Return & Sharpe ratio & Return & Sharpe ratio & \\
\hline 2002 & $6.81 \%$ & 0.114 & $0.166 \%$ & -0.271 & $6.64 \%$ \\
2003 & $63.54 \%$ & -0.074 & $106.569 \%$ & 4.023 & $-43 \%$ \\
2004 & $15.51 \%$ & 1.189 & $6.960 \%$ & 0.177 & $8.55 \%$ \\
2005 & $-1.44 \%$ & -0.537 & $4.517 \%$ & -0.017 & $-5.96 \%$ \\
2006 & $14.55 \%$ & -0.244 & $-4.698 \%$ & -0.627 & $19.24 \%$ \\
2007 & $25.00 \%$ & 1.108 & $29.908 \%$ & 1.198 & $-4.91 \%$ \\
2008 & $-33.84 \%$ & -1.298 & $-46.401 \%$ & -1.404 & $12.56 \%$ \\
2009 & $115.54 \%$ & 5.457 & $75.025 \%$ & 3.155 & $40.52 \%$ \\
2010 & $31.38 \%$ & 1.856 & $44.052 \%$ & 2.396 & $-12.67 \%$ \\
2011 & $14.71 \%$ & 0.441 & $22.958 \%$ & 0.828 & $-8.25 \%$ \\
2012 & $59.30 \%$ & 3.878 & $38.065 \%$ & 2.874 & $21.23 \%$ \\
G. mean & $22.264 \%$ & & $18.647 \%$ & & \\
\hline
\end{tabular}

Table 3. Returns of portfolios selected by PERG-SD ratio compared to the market.

\begin{tabular}{cccccc}
\hline & Low PERG-SD & & \multicolumn{2}{c}{ Market average } & Differential \\
\cline { 1 - 3 } Year & Return & Sharpe ratio & Return & Sharpe ratio & $6.64 \%$ \\
2002 & $6.81 \%$ & 0.114 & $0.166 \%$ & -0.271 & $-18 \%$ \\
2003 & $88.71 \%$ & 5.436 & $106.569 \%$ & 4.023 & $6.46 \%$ \\
2004 & $13.42 \%$ & 0.951 & $6.960 \%$ & 0.177 & $2.27 \%$ \\
2005 & $6.79 \%$ & 0.171 & $4.517 \%$ & -0.017 & $28.68 \%$ \\
2006 & $23.98 \%$ & 1.017 & $-4.698 \%$ & -0.627 & $-9.56 \%$ \\
2007 & $20.35 \%$ & 0.951 & $29.908 \%$ & 1.198 & $21.01 \%$ \\
2008 & $-25.39 \%$ & -1.036 & $-46.401 \%$ & -1.404 & $10.94 \%$ \\
2009 & $85.96 \%$ & 4.425 & $75.025 \%$ & 3.155 & 2.396 \\
2010 & $44.26 \%$ & 2.991 & $44.052 \%$ & 0.828 & $-2.93 \%$ \\
2011 & $20.02 \%$ & 0.696 & $22.958 \%$ & 2.874 & $62.53 \%$ \\
2012 & $100.60 \%$ & 4.787 & $38.065 \%$ & & \\
\hline
\end{tabular}


performances, the results demonstrated that sharpe ratios of the low PERG-SD portfolios were better than those of the market in 9 out of 11 years.

\subsection{Empirical Results from Stock Selection Using PERG Ratio Compared to the Market Average Stock, Using Beta as a Proxy for Risk}

Table 4 shows that when stocks were selected using the lowest PERG-beta ratios as screening, the returns were better than the market average in 6 out of 11 years. When sharpe ratios were used to measure the portfolio performances, the results demonstrated that Sharpe ratios of the low PERG-beta portfolios were better than those of the market in 9 out of 11 years.

\subsection{Empirical Result from Returns Using the 3 Different Screenings}

Table 5 and Figure 1 compare value added of the invested portfolio of 30 stocks selected using PE, PEG, PERG-SD, PERG-beta, with that of the market average. As demonstrated, portfolio using PE yielded the highest average returns thus the highest value added, followed by those using PERG-SD, PERG-beta, and PEG. All selected portfolios with screenings yielded better results compared to the market average.

Table 4. Returns of portfolios selected by PERG-beta ratio compared to the market.

\begin{tabular}{|c|c|c|c|c|c|}
\hline \multicolumn{3}{|c|}{ Low PERG-beta } & \multicolumn{2}{|c|}{ Market average } & \multirow{2}{*}{ Differential } \\
\hline Year & Return & Sharpe ratio & Return & Sharpe ratio & \\
\hline 2002 & $7.73 \%$ & 0.163 & $0.166 \%$ & -0.271 & $7.56 \%$ \\
\hline 2003 & $59.92 \%$ & 5.450 & $106.569 \%$ & 4.023 & $-47 \%$ \\
\hline 2004 & $13.90 \%$ & 1.464 & $6.960 \%$ & 0.177 & $6.94 \%$ \\
\hline 2005 & $2.23 \%$ & -0.312 & $4.517 \%$ & -0.017 & $-2.29 \%$ \\
\hline 2006 & $22.48 \%$ & 1.498 & $-4.698 \%$ & -0.627 & $27.18 \%$ \\
\hline 2007 & $19.26 \%$ & 1.202 & $29.908 \%$ & 1.198 & $-10.65 \%$ \\
\hline 2008 & $-23.30 \%$ & -1.318 & $-46.401 \%$ & -1.404 & $23.11 \%$ \\
\hline 2009 & $98.97 \%$ & 6.385 & $75.025 \%$ & 3.155 & $23.95 \%$ \\
\hline 2010 & $39.45 \%$ & 2.838 & $44.052 \%$ & 2.396 & $-4.60 \%$ \\
\hline 2011 & $17.80 \%$ & 0.741 & $22.958 \%$ & 0.828 & $-5.15 \%$ \\
\hline 2012 & $67.27 \%$ & 7.340 & $38.065 \%$ & 2.874 & $29.21 \%$ \\
\hline G. mean & $24.769 \%$ & & $18.647 \%$ & & \\
\hline
\end{tabular}

Table 5. Value added of the average market compared to those of lowest PE, lowest PEG, lowest PERG-SD and lowest PERG-beta (in Baht).

\begin{tabular}{cccccc}
\hline Year & SET TRI & Low PE & Low PEG & Low PERG-SD & Low PERG-beta \\
\hline 2002 & $1,001,662$ & $1,714,472$ & $1,068,069$ & $1,068,069$ & $1,077,290$ \\
2003 & $2,069,127$ & $5,194,073$ & $1,746,767$ & $2,015,536$ & $1,722,849$ \\
2004 & $2,213,146$ & $4,727,199$ & $2,017,709$ & $2,286,104$ & $1,962,315$ \\
2005 & $2,313,116$ & $4,547,812$ & $1,988,566$ & $2,441,276$ & $2,006,035$ \\
2006 & $2,204,451$ & $5,209,438$ & $2,277,846$ & $3,026,717$ & $2,456,957$ \\
2007 & $2,863,760$ & $5,813,620$ & $2,847,229$ & $3,642,571$ & $2,930,127$ \\
2008 & $1,534,948$ & $3,705,356$ & $1,883,767$ & $2,717,621$ & $2,247,532$ \\
2009 & $2,686,549$ & $8,585,148$ & $4,060,309$ & $5,053,709$ & $4,471,965$ \\
2010 & $3,870,023$ & $14,335,921$ & $5,334,360$ & $7,290,717$ & $6,236,080$ \\
2011 & $4,758,501$ & $21,625,326$ & $6,119,018$ & $8,750,587$ & $7,346,320$ \\
2012 & $6,569,811$ & $37,317,581$ & $9,747,357$ & $17,553,263$ & $12,288,390$ \\
\hline
\end{tabular}




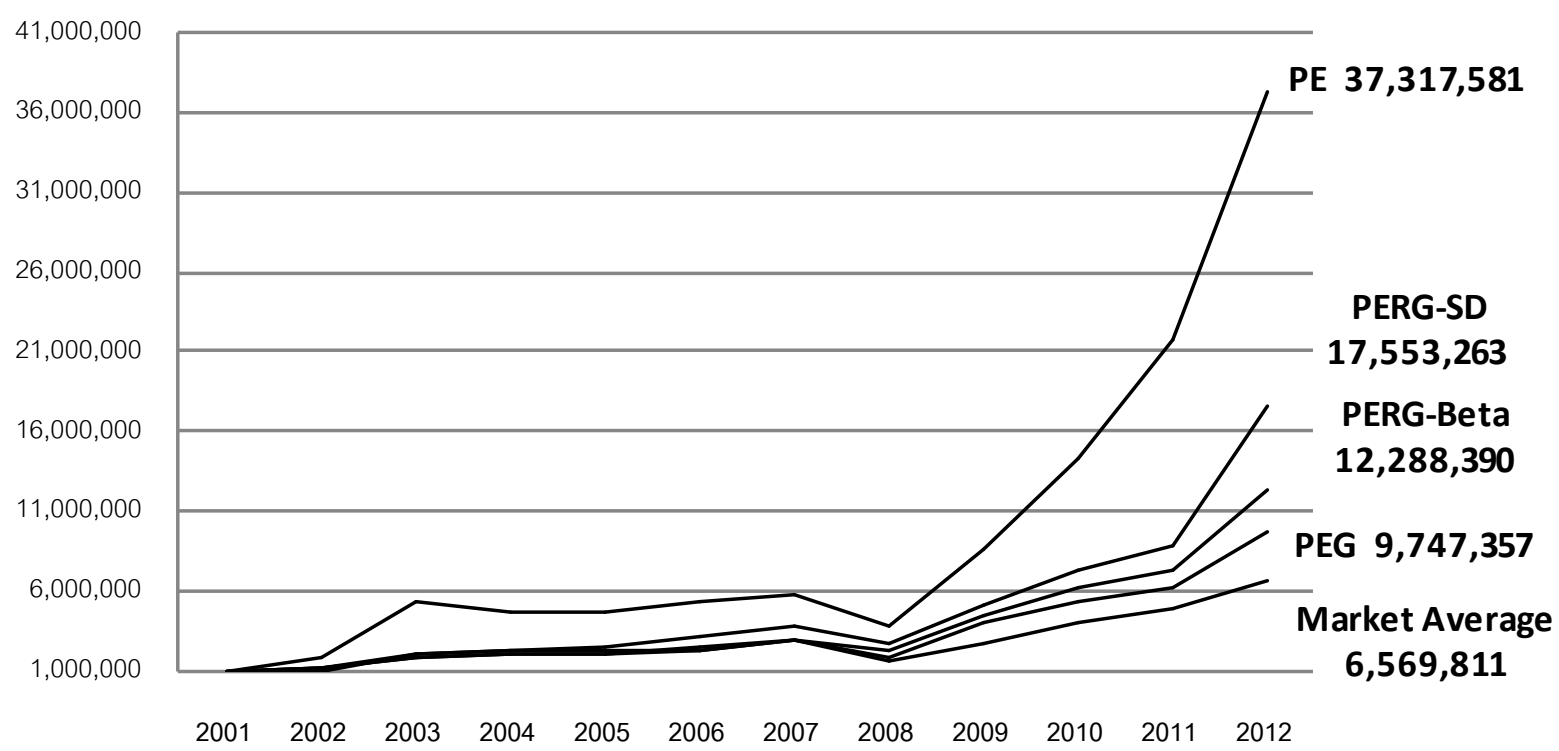

Figure 1. The value added of 4 different portfolios using four different screenings, PE, PEG, PERG-SD, PERG-beta, and that of the market average, over the 11 years period from 2002-2012.

Thus the empirical evidences of this study indicated that during 2002-2012 in the Securities Exchange of Thailand, using PE, PEG, or PERG as screenings for stock selecting, resulted in better portfolio returns than the market average. The results were consistent with the earlier empirical findings in the Thai stock market ${ }^{3}$. PE appeared to be the best screening among the tools used in this study. Moreover, standard deviation of returns appeared to be a better proxy for risk factor than the beta coefficient when used to select value stocks.

\section{Conclusions and Implications}

This study employed the concept of value investing, whereby PE, PEG, and PERG ratios were used for stock screening. The concepts were based on the hypotheses that stocks with low PE ratio, low PEG, and low PERG should generate higher returns than those of the market average. Data from the Securities Exchange of Thailand during 2002-2012 were used to test the hypotheses. Returns from portfolios with low PE, low PEG, and low PERG were computed and found to be better than those of the market average. Proxies for risk, SD and beta, were used to computed PERG. Portfolios of low PERG using Standard Deviation coefficient as risk proxy appeared to provide better performances than those of using beta. All in all, evidences from this study, the PE ratio was shown to be the best screening, providing the highest returns during the period tested.

The implication from this study is that although growth and risk can be incorporated into the screening process for selecting value stocks and providing additional information, traditional screening technique using PE is still working well. Thus for less sophisticated value investors, using PE as a basic screening rule can lead to the outperforming returns. In addition, the portfolio using standard deviation of returns as risk proxy yielded better performance than those of using beta. Thus, when selecting stocks, it could be more beneficial to Thai investors to focus on the total risk rather than the systematic risk.

There are limitations to this study as well. Firstly, due to the lack of data, the time period of 2002-2012 used in the tests is quite short. A longer time period with more comprehensive data could provide better conclusions. In addition, the period tested could be divided into sub-periods according to economic situations and better conclusions could be drawn. A longer time horizon might yield different results. Secondly, proxies for growth and risk used in this study may not be appropriated. Forward looking growth proxy might be better off than the historical growth used. Other risk proxy such as adjusted beta coefficient could also be tested. Thirdly, as suggested in some previous studies, other factors such as skewness [17] [18] might have significant influences on investors' decisions when selecting stocks. Fourthly, alternative methodology to study the effects of PE, growth, and risk could be employed. This could lead to the insight of the real effects of the factors studied on the return in the

\footnotetext{
${ }^{3}$ See details of empirical finding in the Thai market in [12] [14] [16].
} 
stock market in Thailand. Thus, it is recommended that further study may be conducted by incorporating longer time period, different growth and risk proxies, and more factors used as screenings. All in all, the results from this study provide knowledge into the benefits of using fundamentally selected financial ratios in screening value stocks in the developing stock market such as Thailand.

\section{Acknowledgements}

The author would like to Phasin Wanidwaranan, Kornpong Chantarasirirat and Pitsinee Sareewiwatthana for their support in collecting data, testing the hypotheses and editing the paper.

\section{References}

[1] Schatzberg, J.D. and Vora, G. (2009) PEG Investing Strategy: A Revisit. Quarterly Journal of Finance and Accounting, 48, 5-22.

[2] Robichek, A. and Bogue, M. (1971) A Note on the Behavior of Expected Price/Earnings Ratios over Time. Journal of Finance, 26, 731-735. http://onlinelibrary.wiley.com/doi/10.1111/j.1540-6261.1971.tb01726.x/abstract http://dx.doi.org/10.1111/j.1540-6261.1971.tb01726.x

[3] Reinganum, M. (1981) A Misspecification of Capital Asset Pricing: Empirical Anomalies Based on Earnings Yields and Market Values. Journal of Financial Economics, 9, 19-46.

http://www.sciencedirect.com/science/article/pii/0304405X81900192 http://dx.doi.org/10.1016/0304-405X(81)90019-2

[4] Fama, E.F. and French, K.R. (1993) Common Risk Factors in the Returns on Stocks and Bonds. Journal of Financial Economics, 33, 3-56. http://www.sciencedirect.com/science/article/pii/0304405X93900235 http://dx.doi.org/10.1016/0304-405X(93)90023-5

[5] Fama, E.F. and French, K.R. (1996) Multifactor Explanations of Asset Pricing Anomalies. Journal of Finance, 51, 55-84. http://onlinelibrary.wiley.com/doi/10.1111/j.1540-6261.1996.tb05202.x/abstract http://dx.doi.org/10.1111/j.1540-6261.1996.tb05202.x

[6] Petkova, R. and Zhang, L. (2005) Is Value Riskier than Growth? Journal of Financial Economics, 78, 187-202. http://dx.doi.org/10.1016/j.jfineco.2004.12.001

[7] Holt, C.C. (1962) The Influence of Growth Duration on Share Prices. Journal of Finance, 17, 465-475. http://onlinelibrary.wiley.com/doi/10.1111/j.1540-6261.1962.tb04300.x/abstract

[8] Malkiel, B. (1963) Equity Yields, Growth, and the Structure of Share Prices. American Economic Review, 53, 10041031.

[9] Easton, P. (2004) PE Ratios, PEG Ratios, and Estimating the Implied Expected Rate of Return on Equity Capital. The Accounting Review, 79, 73-95. http://papers.ssrn.com/sol3/papers.cfm?abstract_id=423601 http://dx.doi.org/10.2308/accr.2004.79.1.73

[10] Estrada, J. (2005) Adjusting P/E Ratios by Growth and Risk: The PERG Ratio. International Journal of Managerial Finance, 1, 187-203. http://www.emeraldinsight.com/journals.htm?articleid=1523923\&show=pdf http://dx.doi.org/10.1108/17439130510619631

[11] Sareewiwatthana, P. (2011) Value Investing in Thailand: The Test of Basic Screening Rules. International Review of Business Research Papers, 7, 1-13. http://www.bizresearchpapers.com/1.\%20Paiboon.pdf

[12] Maneesilasan, N. (2011) GARP Investing in Thailand. Unpublished, National Institute of Development Administration, Bangkok.

[13] Sareewiwatthana, P. (2012) Value Investing in Thailand: Evidence from the Use of PEG. Technology and Investment, 3, 113-120. http://www.scirp.org/journal/PaperInformation.aspx?paperID=19395\#.U0_q4VWSxpw

[14] Panyagometh, K. (2012) Weight and Stock Selections for Equity Portfolio Management: Evidence from the Stock Exchange of Thailand. Business and Management Review, 2, 20-27. http://www.businessjournalz.org/articlepdf/BMR-2701Sep2(7)12c.pdf

[15] Sareewiwatthana, P. (2013) Common Financial Ratios and Value Investing in Thailand. Journal of Finance and Investment Analysis, 2, 69-85. http://www.scienpress.com/Upload/JFIA/Vol\%202_3_6.pdf

[16] Sharpe, W.F. (1966) Mutual Fund Performance. The Journal of Business, 39, 119-138. http://dx.doi.org/10.1086/294846

[17] Chunhachinda, P., Dandapani, K., Hamid, S. and Prakash, A.J. (1997) Portfolio Selection and Skewness: Evidence from International Stock Markets. Journal of Banking \& Finance, 21, 143-167. http://www.sciencedirect.com/science/article/pii/S0378426696000325 
http://dx.doi.org/10.1016/S0378-4266(96)00032-5

[18] Tang, G.Y.N. and Shum, W.C. (2003) The Relationships between Unsystematic Risk, Skewness and Stock Returns During up and down Markets. International Business Review, 12, 523-541.

http://www.sciencedirect.com/science/article/pii/S096959310300074X

http://dx.doi.org/10.1016/S0969-5931(03)00074-X 